\title{
Effects of remote, retroactive intercessory prayer on outcomes in patients with bloodstream infection: randomised controlled trial
}

\author{
Leonard Leibovici
}

\section{Department of Medicine, Beilinson Campus, Rabin Medical Center, Petah-Tiqva 49100 , Israel \\ Leonard Leibovici professor \\ leibovic@post tau.ac.il}

BMJ 2001;323:1450-1

\begin{abstract}
Objective To determine whether remote, retroactive intercessory prayer, said for a group of patients with a bloodstream infection, has an effect on outcomes. Design Double blind, parallel group, randomised controlled trial of a retroactive intervention. Setting University hospital.

Subjects All 3393 adult patients whose bloodstream infection was detected at the hospital in 1990-6. Intervention In July 2000 patients were randomised to a control group and an intervention group. A remote, retroactive intercessory prayer was said for the well being and full recovery of the intervention group.
\end{abstract}

Main outcome measures Mortality in hospital, length of stay in hospital, and duration of fever.

Results Mortality was 28.1\% $(475 / 1691)$ in the intervention group and 30.2\% (514/1702) in the control group $(\mathrm{P}$ for difference $=0.4)$. Length of stay in hospital and duration of fever were significantly shorter in the intervention group than in the control group $(\mathrm{P}=0.01$ and $\mathrm{P}=0.04$, respectively).

Conclusions Remote, retroactive intercessory prayer said for a group is associated with a shorter stay in hospital and shorter duration of fever in patients with a bloodstream infection and should be considered for use in clinical practice.

\section{Introduction}

Two randomised controlled trials tested the effect of remote intercessory prayer (praying for persons unknown) on outcomes in patients admitted to an intensive coronary care unit. ${ }^{12}$ Both studies showed a beneficial effect. A recent systematic review of the efficacy of distant healing concluded that "approximately $57 \%$ (13 of 23) of the randomised, placebo-controlled trials of distant healing ... showed a positive treatment effect" and that "the evidence thus far warrants further study."'

The purpose of the present study was to extend these observations to patients with another severe disorder, bloodstream infection. As we cannot assume a priori that time is linear, as we perceive it, ${ }^{4}$ or that God is limited by a linear time, as we are, ${ }^{5}$ the intervention was carried out 4-10 years after the patients' infection and hospitalisation. The hypothesis was that remote, retroactive intercessory prayer reduces mortality and shortens the length of stay in hospital and duration of fever.

\section{Methods}

All adult patients whose bloodstream infection was detected at a university hospital (Rabin Medical Center, Beilinson Campus) in Israel during 1990-6 were included in the study. Bloodstream infection was defined as a positive blood culture (not resulting from contamination) in the presence of sepsis.

In July 2000 a random number generator (Proc Uniform, SAS, Cary, NC, USA) was used to randomise the patients into two groups. A coin was tossed to designate the intervention group. A list of the first names of the patients in the intervention group was given to a person who said a short prayer for the well being and full recovery of the group as a whole. There was no sham intervention.

Three primary outcomes were compared: the number of deaths in hospital, length of stay in hospital from the day of the first positive blood culture to discharge or death, and duration of fever. Patients were defined as having fever on a specific day if one of three temperature measurements taken on that day showed a temperature of $>37.5^{\circ} \mathrm{C}$.

The $\chi^{2}$ test was used to test for the significance of the results shown in the tables. As most of the continuous variables did not have a normal distribution, the Wilcoxon rank sum test was used for comparisons.

\section{Results}

Of 3393 patients with a bloodstream infection, 1691 patients were randomised to the intervention group and 1702 to the control group. No patients were lost to

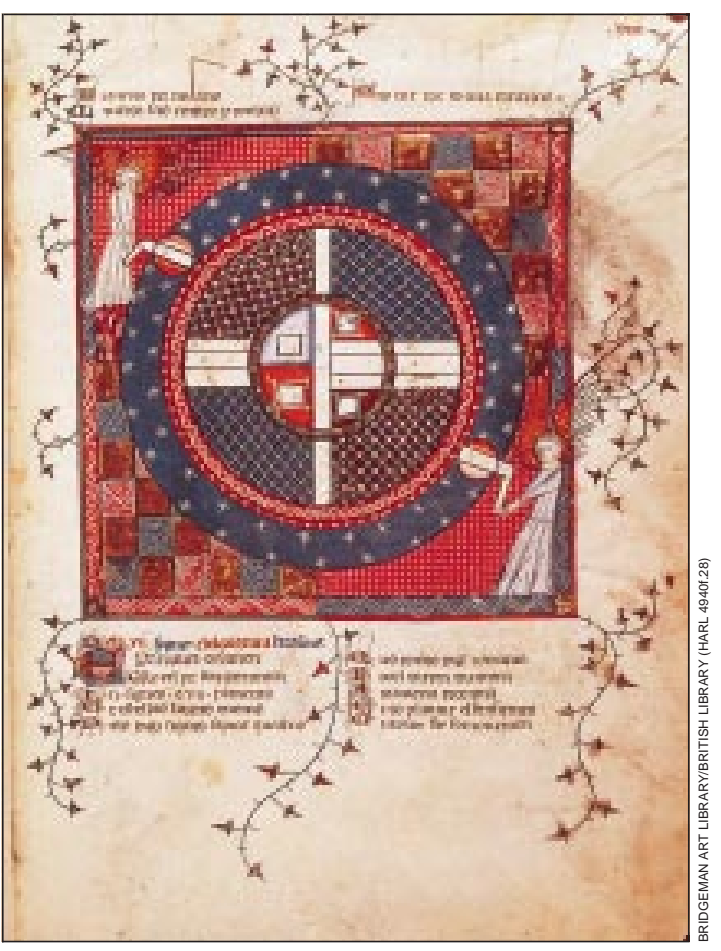

Angels make the universe turn-and time moves on 


\section{What is already known on this topic}

Two randomised controlled trials of remote intercessory prayer (praying for persons unknown) showed a beneficial effect in patients in an intensive coronary care unit

A recent systematic review found that $57 \%$ of the randomised, placebo controlled trials of distant healing showed a positive treatment effect

\section{What this study adds}

Remote intercessory prayer said for a group of patients is associated with a shorter hospital stay and shorter duration of fever in patients with a bloodstream infection, even when the intervention is performed $4-10$ years after the infection

follow up. The groups were similar with regard to the main risk factors for death (table 1 ).

Mortality was $28.1 \%(475 / 1691)$ in the intervention group and 30.2\% (514/1702) in the control group ( $\mathrm{P}$ for difference $=0.4$ ). The length of stay in hospital and duration of fever were significantly shorter in the intervention group $(\mathrm{P}=0.01$ and $\mathrm{P}=0.04$, respectively) (table 2).

\section{Discussion}

Remote, retroactive intercessory prayer was associated with a shorter stay in hospital and a shorter duration of fever in patients with a bloodstream infection. Mortality was lower in the intervention group, but the difference between the groups was not significant. A larger study might have shown a significant reduction in mortality.

The similarity in the risk factors in the two groups showed that the randomisation and allocation concealment were good. The very design of the study assured perfect blinding to patients and medical staff of allocation of patients and even the existence of the trial. Regrettably, the very same design meant that it was not possible to obtain the informed consent of the patients.

No mechanism known today can account for the effects of remote, retroactive intercessory prayer said for a group of patients with a bloodstream infection. However, the significant results and the flawless design prove that an effect was achieved. To quote Harris et al: "when James Lind, by clinical trial, determined that lemons and limes cured scurvy aboard the HMS Salisbury in 1753, he not only did not know about ascorbic acid, he did not even understand the concept of a 'nutrient.' There was a natural explanation for his findings that would be clarified centuries later, but his inability to articulate it did not invalidate his observations."

\section{Conclusion}

Remote, retroactive intercessory prayer can improve outcomes in patients with a bloodstream infection. This intervention is cost effective, probably has no adverse effects, and should be considered for clinical practice. Further studies may determine the most
Table 1 Baseline characteristics of patients. Values are percentages in each group, unless stated otherwise. None of the differences between the groups was significant

\begin{tabular}{lcc} 
Characteristic & Intervention group $(\mathbf{n}=\mathbf{1 6 9 1 )}$ & Control group ( $\mathbf{n = 1 7 0 2 )}$ \\
\hline Women & 46.3 & 48.5 \\
\hline Median (range) age (years) & $72(18-101)$ & $72(18-99)$ \\
\hline Source of infection: & & \\
\hline Lungs & 8.3 & 9.4 \\
\hline Urinary tract & 31.3 & 28.9 \\
\hline Intra-abdominal & 9.5 & 8.9 \\
\hline Soft tissues & 7.5 & 7.6 \\
\hline Endocarditis & 3.5 & 3.3 \\
\hline Neutropenic fever & 3.5 & 2.7 \\
\hline Intravascular line & 6.3 & 6.4 \\
\hline Other & 7.8 & 9.6 \\
\hline Unknown & 22.3 & 23.2 \\
\hline Septic shock & 11.2 & 11.8 \\
\hline Neutropenia & 5.7 & 5.8 \\
\hline Infected while in hospital & 40.2 & 41.9 \\
\hline Median (range) creatinine $(\mathrm{mg} / \mathrm{dl})$ & $1.2(0.2-14.8)$ & $1.2(0.2-15.0)$ \\
\hline Median (range) albumin $(\mathrm{mg} / \mathrm{dl})$ & $3.8(1.1-5.1)$ & $3.8(1.5-5.0)$ \\
\hline
\end{tabular}

Table 2 Numbers of days' stay in hospital and duration of fever

\begin{tabular}{lcccccc} 
& Minimum & $\begin{array}{c}\text { Lower } \\
\text { quartile }\end{array}$ & Median & $\begin{array}{c}\text { Upper } \\
\text { quartile }\end{array}$ & Maximum & P \\
\hline Stay in hospital: & & & & & & \\
\hline Intervention & 0 & 4 & 7 & 13 & 165 & 0.01 \\
\hline Control & 0 & 4 & 8 & 16 & 320 & \\
\hline Duration of fever: & & & & & & \\
\hline Intervention & 0 & 1 & 2 & 4 & 49 & 0.04 \\
\hline Control & 0 & 1 & 2 & 5 & 50 & \\
\hline
\end{tabular}

effective form of this intervention and its effect in other severe conditions and may clarify its mechanism.

Contributors: LL planned and performed the study and is the guarantor.

Funding: None.

Competing interests: None declared.

1 Harris WS, Gowda M, Kolb JW, Strychacz CP, Vacek JL, Jones PG, et al. A randomized, controlled trial of the effects of remote, intercessory prayer on outcomes in patients admitted to the coronary care unit. Arch Intern on outcomes in patien

2 Byrd RC. Positive therapeutic effects of intercessory prayer in a coronary care unit population. South Med J 1988;81:826-9.

3 Astin JA, Harkness E, Ernst E MD. The efficacy of "distant healing": a systematic review of randomized trials. Ann Intern Med 2000;132:903-10.

4 Landsberg PT, Vickers J. Thermodynamics: conflicting arrows of time Nature 2000:403:609.

5 Borges JL. A new refutation of time. In: Labyrinths. Harmondsworth: Penguin, 1970.

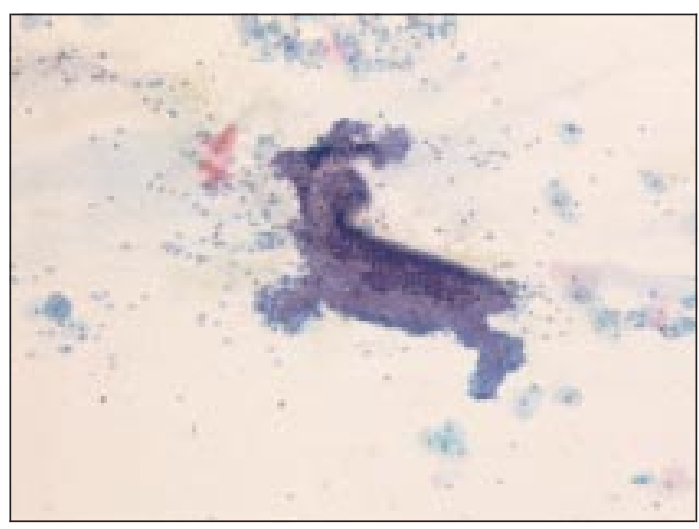

This red nosed reindeer is actually a group of endocervical cells from a cervical smear. Note the squamous cells in the background. First spotted by Phil Bullock, laboratory manager, and submitted by Neil A Shepherd, professor, department of histopathology, Gloucestershire Hospitals, Gloucester GL1 3NN 